
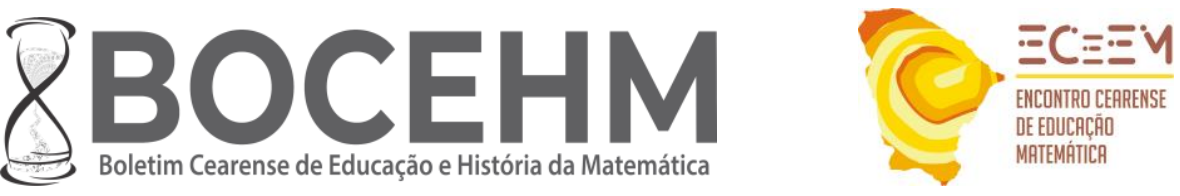

ISSN: $2447-8504$

DOI: $10.30938 /$ bocehm.v8i23.4876

\title{
INTERAÇÕES VIRTUAIS ACERCA DO PROCESSO DE ALFABETIZAÇÃO MATEMÁTICA NA PERSPECTIVA DO LETRAMENTO
}

\section{VIRTUAL INTERACTIONS ON THE MATHEMATICAL LITERACY PROCESS IN THE PERSPECTIVE OF LETTERING}

\author{
Mariany Fonseca Garcia ${ }^{1}$; Danielle Abreu Silva ${ }^{2}$, Klinger Teodoro Ciríaco ${ }^{3}$
}

\begin{abstract}
RESUMO
Tomamos como objeto de reflexão e análise encaminhamentos e resultados de uma experiência de formação continuada de professores(as) acerca do processo de alfabetização matemática na perspectiva do letramento. Buscamos no contexto extensionista de uma atividade promovida pela Universidade Federal de São Carlos - UFSCar, apresentar e problematizar em que medida interações virtuais assíncronas no Facebook constituem-se eixo catalisador de compartilhamento de práticas profissionais em que a literatura infantil representa campo promissor ao ler, escrever e resolver problemas em Educação Matemática nos anos iniciais, particularmente em turmas de $1^{\circ}$ ao $3^{\circ}$ ano, sendo este o objetivo do artigo. O referencial teórico abarca discussões sobre alfabetização, letramento e alfabetização matemática na perspectiva do letramento por meio de projetos de ensino e sequências didáticas. Em termos metodológicos, validamo-nos de uma dinâmica de colaboração e interação virtual cujo o foco era que os/as docentes compartilhassem suas práticas profissionais em que a linguagem ocupou/ocupa posição de destaque no trabalho pedagógico com base na indicação de títulos de livros de histórias infantis de natureza matemática à problematização via projetos de ensino e/ou sequências didáticas. Como resultado central, podemos inferir que a adoção de ambientes virtuais de aprendizagem constituem-se fontes ricas
\end{abstract}

1 Licencianda em Pedagogia pela Universidade Federal de São Carlos (UFSCar). Integrante do "MANCALA - Grupo de Estudos e Pesquisas em Educação Matemática, Cultura e Formação Docente" (CNPq/UFSCar), São Carlos, SP, Brasil. Rodovia Washington Luís S/N KM 235 - Jardim Guanabara, São Carlos, SP, Brasil, CEP: 13565-905. E-mail: marianyfonsecagarcia@gmail.com.

(iD) ORCID iD: https://orcid.org/0000-0002-7213-3457.

2 Pedagoga pela Universidade Federal de Mato Grosso do Sul (UFMS, Campus Naviraí). Integrante do "MANCALA - Grupo de Estudos e Pesquisas em Educação Matemática, Cultura e Formação Docente" (CNPq/UFSCar). Mestranda em Educação na linha de pesquisa "Educação em Ciências e Matemática" pela Universidade Federal de São Carlos (UFSCar), São Carlos, SP, Brasil. Rodovia Washington Luís S/N KM 235 - Jardim Guanabara, São Carlos, SP, Brasil, CEP: 13565-905. E-mail: abreu.danni@ gmail.com.

ORCID iD: https://orcid.org/0000-0001-9510-8097.

${ }^{3}$ Doutor em Educação pela Faculdade de Ciências e Tecnologia da Universidade Estadual Paulista "Júlio de Mesquita Filho" (FCT/UNESP, Presidente Prudente-SP). Professor Adjunto do Departamento de Teorias e Práticas Pedagógicas (DTPP) do Centro de Educação e Ciências Humanas (CECH) da Universidade Federal de São Carlos (UFSCar), São Carlos, SP, Brasil. Líder do "MANCALA - Grupo de Estudos e Pesquisas em Educação Matemática, Cultura e Formação Docente" (CNPq/UFSCar). Rodovia Washington Luís S/N KM 235 - Jardim Guanabara, São Carlos, SP, Brasil, CEP: 13565-905. E-mail: klinger.ciraco@ufscar.br

(iD) ORCID iD: https://orcid.org/0000-0003-1694-851X. 
e promissoras de compartilhamento de práticas, desde que mediadas de forma colaborativa e interativa, o que para nós ocorreu na proposta em apreciação. Além disso, frente ao trabalho docente remoto durante a pandemia, recorrer às redes sociais como recurso pedagógico possibilitou tornar o processo mais natural, dado que contribuiu para fluir positivamente o sentimento de pertença dos partícipes.

Palavras-chave: Interações virtuais; Formação continuada de professores; Alfabetização matemática; Literatura Infantil.

\begin{abstract}
We take as an object of reflection and analysis guidelines and results of an experience of continuing education of teachers about the process of mathematical literacy in the perspective of literacy. We seek in the extension context of an activity promoted by the Federal University of São Carlos - UFSCar, to present and discuss the extent to which asynchronous virtual interactions on Facebook constitute a catalyst for sharing professional practices in which children's literature represents a promising field when reading, writing and solve problems in Mathematics Education in the early years, particularly in classes from 1st to 3rd year, this being the objective of the article. The theoretical framework includes discussions on literacy, literacy and mathematical literacy from the perspective of literacy through teaching projects and didactic sequences. In methodological terms, we are validated by a dynamic of collaboration and virtual interaction whose focus was for teachers to share their professional practices in which language has occupied / occupies a prominent position in pedagogical work based on the indication of titles of textbooks. children's stories of a mathematical nature to problematization via teaching projects and / or didactic sequences. As a central result, we can infer that the adoption of virtual learning environments are rich and promising sources for sharing practices, provided they are mediated in a collaborative and interactive way, which for us occurred in the proposal under consideration. In addition, in the face of remote teaching work during the pandemic, using social networks as a pedagogical resource made it possible to make the process more natural, given that it contributed to positively flow the participants' feeling of belonging.
\end{abstract}

Keywords: Virtual interactions; Continuing teacher education; Mathematical literacy; Children's literature. 


\section{Introdução}

Para dar conta da discussão proposta neste artigo, são apresentadas experiências de trabalho remoto em um contexto de aprendizagens e interações virtuais com um grupo de professores(as) que ensinam Matemática no ciclo da alfabetização ( $1^{\circ}$ ao $3^{\circ}$ ano) a partir de uma atividade de extensão promovida pela Universidade Federal de São Carlos - UFSCar, Campus São Carlos-SP.

Em decorrência da suspensão das aulas presenciais, devido a pandemia de COVID-19, o semestre na UFSCar teve sua retomada em 31 de agosto de 2020 e, com isso, a exploração de "Ambientes Virtuais de Aprendizagens" (AVA) - ao que incluímos o Facebook - colocou-se como alternativa de trabalho docente remoto para oferta tanto de disciplinas na graduação quanto para atividades extensionistas, como o caso que aqui destacamos. Trata-se da ação "Alfabetização matemática na perspectiva do letramento: sequência didática e projetos de ensino" (Processo: 23112.104214/201919), a qual contou com a participação de professores(as) dos anos iniciais do Ensino Fundamental de distintas regiões brasileiras, haja vista que, com a realização à distância, houve ampla divulgação nas redes sociais e isso gerou público-alvo que atingiu 64 inscritos(as). Seus partícipes englobam os Estados das seguintes regiões: Norte, CentroOeste, Sudeste e Sul do Brasil.

\section{O processo de alfabetização matemática na perspectiva do letramento}

A alfabetização matemática na perspectiva do letramento vem sendo o foco de investigações, bem como da tentativa de implementação curricular no Estado de São Paulo nos últimos anos como, por exemplo, nas discussões do projeto Educação Matemática nos Anos Iniciais - EMAI (PIRES, 2000; BRASIL, 2014), material este adotado pelas escolas estaduais paulistas atualmente. Face a demanda emergente que se coloca em decorrência das práticas de promoção à cidadania efetivadas pela escola, o ensino dos conteúdos matemáticos merece destaque e, para que a visão de formar sujeitos críticos-reflexivos se concretize, mudanças na concepção e na atuação profissionais se colocam urgentes e necessárias.

Em decorrência disso, a intenção basilar da atividade de extensão que desenvolvemos residiu no processo de instrumentalização das práticas profissionais de um grupo de professores que ensinam Matemática de escolas públicas de distintas regiões 
do Brasil, bem como de acadêmicos do curso de licenciatura em Pedagogia da Universidade Federal de São Carlos - UFSCar - em ações de ensino e extensão que visaram planejamento de intervenções futuras no ciclo da alfabetização ( $1^{\circ}$ ao $3^{\circ}$ ano) por meio de sequências didáticas e projetos de ensino, dado referencial teórico de estudo do grupo.

Danyluk (2002) conceitua o ato de aprender a ler e escrever a linguagem matemática, nos primeiros anos escolares, como alfabetização matemática. "Ser alfabetizado em matemática, então, é entender o que se lê e escrever o que se entende a respeito das primeiras noções de aritmética, geometria e lógica" (DANYLUK, 1988, p. 58).

É certo que alfabetizar e letrar são processos que se diferenciam em termos conceituais, mas, também é fato que estes se inter-relacionam em situações de aprendizagem escolar e do atendimento às demandas de vida social. Ou seja, alfabetização e letramento caminham juntos. Para Soares (2003), a questão é alfabetizar letramento e reportando-nos à Educação Matemática na infância seria, então, " alfabetizar matematicamente numerando" (SILVA; MARANGONI; FURLAN; CARBONI, 2016).

Para este fim, a organização do trabalho pedagógico, em termos de garantir à criança tanto seus direitos de aprendizagem matemática, tal como descritos pelo Pacto Nacional pela Alfabetização na Idade Certa - PNAIC - (BRASIL, 2014), quanto o acesso a diferentes gêneros textuais discursivos, orais e escritos de natureza matemática, tornase objetivo da escola e de uma prática docente que se quer alfabetizar na perspectiva do letramento matemático.

Ortega e Parisotto (2016, p. 55), em uma análise dos cadernos do PNAIC (de Linguagem - 2013 - e de Alfabetização Matemática - 2014), pontuam que:

Ao nos determos nos significados dos conceitos e procedimentos matemáticos,
estamos privilegiando a dimensão semântica. É fundamental que haja uma
integração das dimensões sintática e semântica. Uma das formas de viabilizar
essa integração é a fala: a oralidade auxilia a criança nos primeiros passos do
pensar matematicamente.

Assim, para que a alfabetização matemática na perspectiva do letramento se efetive, é importante que o/a professor/a intensifique atividades que evidenciam a leitura/escrita e trabalhe técnicas de interpretação textual no campo da Educação Matemática para que contribua para a exploração e vivências com os conteúdos e 
proporcione melhor compreensão dos enunciados matemáticos, no caso da resolução de problemas e também no trabalho com projetos de ensino que integrem literatura e Matemática.

De acordo com Cohn (2017) a literatura infantil, enquanto recurso didático, tem múltiplos sentidos. Um deles é o de despertar os conhecimentos fazendo com que se torne mais eficaz a interação da criança com seu momento de aprendizado, este tipo de prática quando desenvolvida de forma interdisciplinar em uma sequência didática e/ou projetos de ensino também "[...] pode ser posta a serviço da matemática, uma vez que propicia o trabalho conjunto desta e da língua materna e, por meio da narrativa, é possível apropriarse dos conhecimentos" (SOUZA; CARNEIRO; 2015, p. 298).

Em síntese, compreendemos, diante do exposto, que a adoção da sequência didática e dos projetos de ensino são metodologias valiosas. Portanto, é necessário que o/a professor/a implemente tais possibilidades de organização de seu trabalho pedagógico, pois estes podem contribuir para a aquisição de novas habilidades e a consolidação de conhecimentos das crianças do ciclo da alfabetização, o que reforça a necessidade de um trabalho em parceria com a Universidade para efetivação deste tipo de prática, em um movimento de interlocução com professores/as em exercício e futuros/as professores/as (acadêmicos/as de Pedagogia).

\section{Pressupostos metodológicos da formação}

O trabalho transcorreu em uma ação extensionista de cunho interventivo nos anos iniciais do Ensino Fundamental, especificamente no campo da formação continuada de professores/as que atuavam em turmas do ciclo da alfabetização ( $1^{\circ}$ ao $3^{\circ}$ ano). Além destes/as profissionais, participaram da atividade formativa acadêmicos/as de Pedagogia da UFSCar. Neste contexto, professores/as e futuros/as professores/as uniram esforços para constituir um grupo de trabalho colaborativo (FIORENTINI, 2004; CIRÍACO, 2016) virtual com vista à estudos de orientação teórica, reflexão, planejamento de sequências didáticas e projetos de ensino interdisciplinares com o objetivo de trabalhar conteúdos matemáticos na perspectiva do letramento, particularmente com materiais paradidáticos (literatura infantil). Em um ambiente de trabalho colaborativo, existem algumas características que estiveram presentes na ação de extensão que implementamos foram: 
1) voluntariedade, identidade e espontaneidade; 2) liderança compartilhada ou corresponsabilidade; e 3) apoio e respeito mútuo (CIRÍACO, 2016).

A colaboração é colocada como fonte direta de produção de dados neste estudo, justamente porque, como aponta Hall e Wallace (1993), ser esta uma maneira de trabalho em que as pessoas combinam recursos, delineiam objetivos e elaboram estratégias de atuação comuns em determinados espaço-tempos. "O trabalho colaborativo possibilita, além disso, o resgate de valores como o compartilhamento e a solidariedade - que se foram perdendo ao longo do caminho trilhado por nossa sociedade, extremamente competitiva e individualista" (DAMIANI, 2008, p. 225), os quais entendemos fundamentais ao tempo presente, o da pandemia de COVID-19, em que estamos todos(as) em isolamento social.

Realizamos encontros síncronos (via Google Meet) semanais nas quartas-feiras, no horário das $17 \mathrm{~h} 30 \mathrm{~min}$ às $19 \mathrm{~h} 00 \mathrm{~min}$, bem como atividades assíncronas (via Facebook) em que perspectivamos que ocorrem compartilhamento de práticas profissionais acerca das temáticas estudadas pelo grupo.

Os/as participantes do projeto foram 64 pessoas, sendo 53 professores/as de turmas do ciclo da alfabetização; 7 coordenadoras pedagógicas; e 4 estudantes de licenciatura em Pedagogia da UFSCar. A grande maioria dos/as docentes lecionava no ciclo de alfabetização ( $1^{\circ}$ ao $3^{\circ}$ ano) e estava em exercício quando do momento do início da ação.

As atividades síncronas e assíncronas foram guiadas pelas seguintes fases, dentre as quais destacamos para exploração neste texto a $2^{\mathrm{a}}$, de formação:

1. Aprofundamento da equipe em referenciais teóricos e metodológicos dos estudos do letramento e do letramento matemático, bem como na definição de sequência didática e projetos de ensino nas discussões semanais síncronas pelo meet;

2. Interações assíncronas a partir de um grupo fechado no Facebook em que problematizamos os assuntos estudados nos encontros síncronos por meio de tarefas de compartilhamento de práticas que buscassem contribuir para a ampliação do repertório de trabalho com a Educação Matemática nos anos iniciais; e

3. Elaboração/planejamento de uma sequência didática que apresentasse as possibilidades interventivas em ações futuras pós-pandemia. 
Frente à especificidade do trabalho realizado, acreditamos que pela dinâmica formativa a experiência do projeto pode servir de mote para reflexões da organização do trabalho pedagógico com a Educação Matemática nos anos iniciais em tempos de pandemia, como também para ampliação do repertório didático-pedagógico dos/as envolvidos/as (professores/as e futuros/as professores/as) em ambientes virtuais de aprendizagem e ainda em como a tecnologia e os recursos comunicacionais de interação, aqui o Facebook, podem constituírem-se fontes de aprendizagem e formação.

\section{Descrição e análise de dados}

As tarefas assíncronas destinadas envolveram leitura de textos, produção de vídeos, preenchimento de formulários, escrita de uma narrativa e postagem de uma atividade no grupo privado do Facebook, este destinado ao projeto de extensão, cuja proposta foi eleger e compartilhar um título de literatura infantil que fizesse menção à natureza paradidática da Matemática e, além disso, deveriam descrever como seria trabalhado o livro em turmas do $1^{\circ}$ ao $3^{\circ}$ ano do Ensino Fundamental, bem como os conteúdos matemáticos que poderiam ser discutidos a partir da problematização da história. Sobre a literatura infantil nas aulas de Matemática, entendemos que esta união pode proporcionar interesse e motivação nas crianças, de forma que elas obtenham mais sucesso na disciplina, tornando possível um maior aprofundamento dos conteúdos matemáticos (CIRÍACO; SANTOS, 2020).

Segundo Franco e Castanheira (2016) o Facebook apresenta notório potencial para ser um Ambiente Virtual de Aprendizagem (AVA). Sendo assim, em concordância com as autoras, no presente texto, nos deteremos nesta descrição e análise em discutir as interações ocorridas entre as cursistas nas postagens da atividade de indicação de livro de literatura na referida rede social. A figura 1 ilustra a página inicial do grupo constituída no Facebook. 
Figura 1 - Ambiente de interação virtual no Facebook.

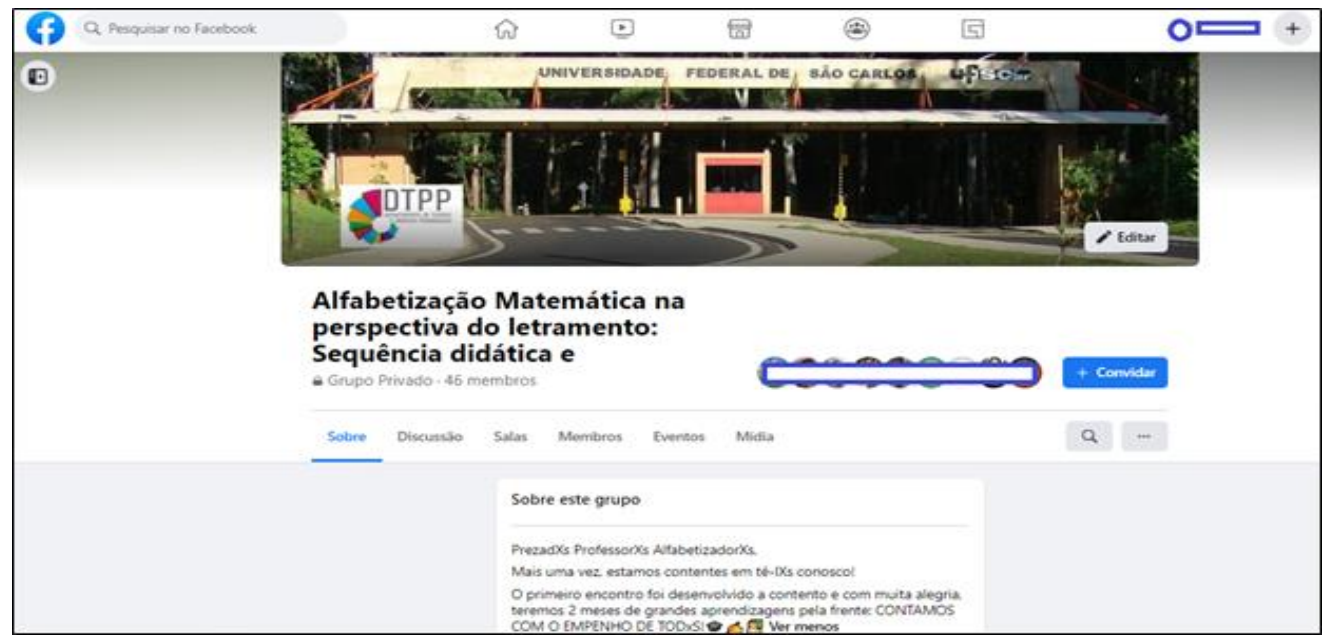

Fonte: Página da Web Facebook - grupo elaborado pelos autores - (2021).

Diante das formas de uso recorrente da presente rede social, defendemos que sua adoção pode representar campo de fortalecimento de práticas formativas, haja vista que é dado recorrente que muitas pessoas interagem e ficam horas significativas neste ambiente. Compreendemos que os espaços que promovem intencionalidade educativa "[...] representam ambientes intelectuais, culturais, sociais e psicológicos que facilitam e sustentam a aprendizagem, enquanto promovem a interação, a colaboração e o desenvolvimento de um sentimento de pertença dos seus membros" (MOREIRA; JANUÁRIO, 2014, p. 74), o que ocorreu na experiência da extensão ora relatada sob nossa avaliação ocorreu.

Sendo assim, foi nesse ambiente de aprendizagem e interação que as professoras compartilharam 38 títulos de literatura infantil, dentre os quais destacaremos 3 para problematização neste trabalho.

O primeiro título é "Poemas Problemas" de Renata Bueno, esse título foi recomendado por três professoras I.S.R, L.R.A.P e A.P.R $\mathbf{R}^{\mathbf{4}}$ que, segundo elas, é um livro envolvente, cheio de charadas, rimas, enigmas e poemas matemáticos.

\footnotetext{
${ }^{4}$ Com o intuito de garantir o anonimato das pessoas que contribuíram para a construção do presente estudo, escolhemos identificá-las por meio das letras iniciais de seus nomes e sobrenomes.
} 
Figura 2 - Indicação do livro "Poemas problemas".

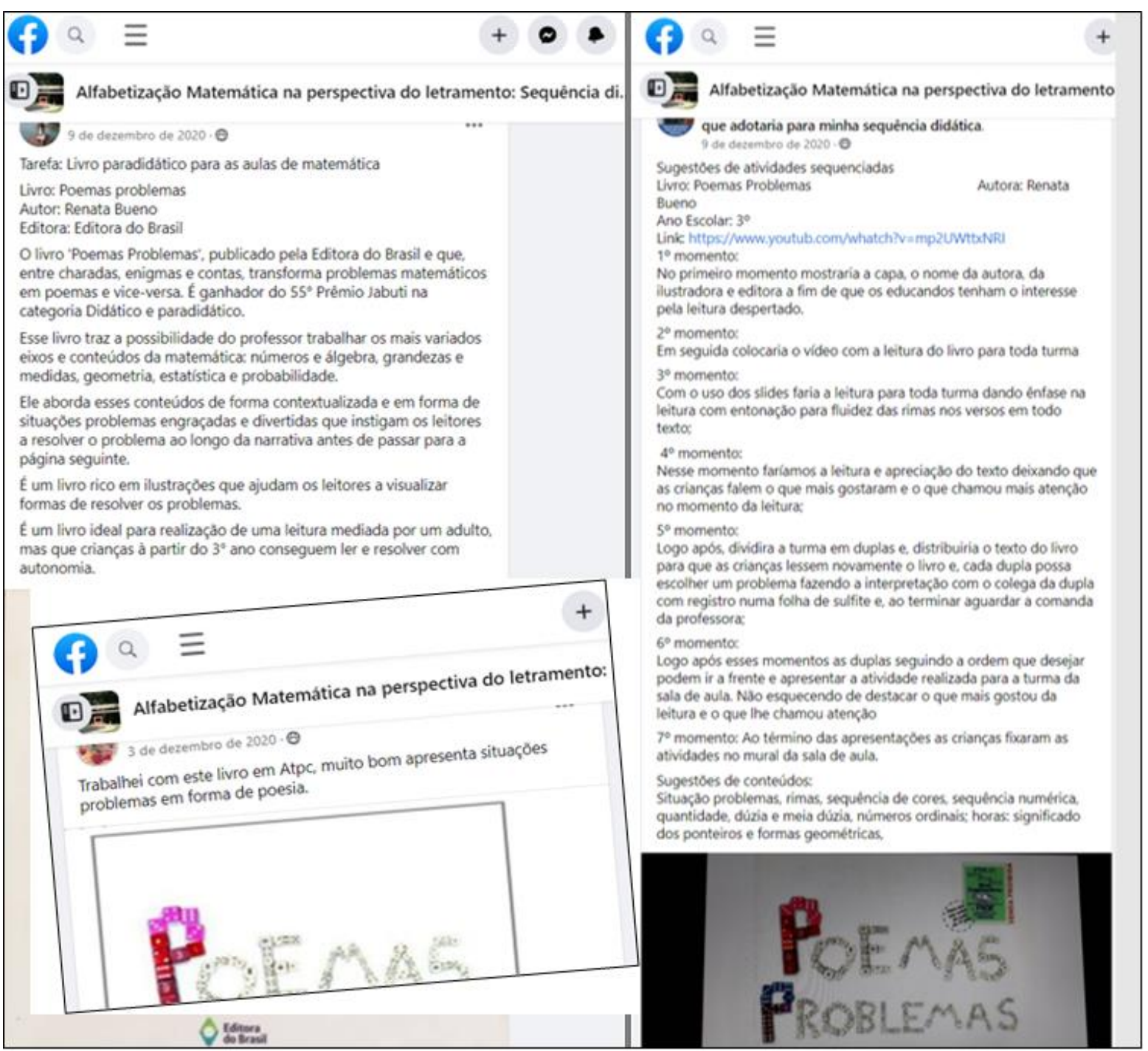

Fonte: Práticas compartilhadas na página da Web do grupo do Facebook (2021).

Como pode ser observado na figura 2, a primeira professora (A.P.R) destaca brevemente uma apresentação geral do livro e de como os conteúdos fazem referência à natureza matemática. Já a professora L.R.A.P menciona que trabalhou o livro em uma "Aula de Trabalho Pedagógico Coletivo" (ATPC) e destaca a qualidade do mesmo por apresentar situações-problemas em forma de poesia. No entanto, a professora I. S.R descreve com maiores detalhes como seria trabalhado em uma turma de $3^{\circ}$ ano do Ensino Fundamental e o "passo a passo" de sua sequência didática. Além disso, também indica sugestões de abordagem contextualizada a partir de situações-problemas que podem envolver aspectos de quantidade, dúzia e meia dúzia, números ordinais; horas (significado 
dos ponteiros), formas geométricas, sequência numérica e de cores (com prenúncio de sequências e padrões da linguagem pré-algébrica).

Percebemos nas três propostas que as professoras trouxeram importantes contribuições que possibilitaram o compartilhamento de ideias, e assim, entendemos que "[...] a participação em redes de formação coletiva possa ser um suporte de práticas de formação baseadas na partilha e no diálogo, no sentido de problematizar implicações e possibilidades encontradas na formação e na prática docente [...]" (SANTOS; MELIM; PANIAGO, 2017, p. 17).

O segundo título que destacamos é "Com que roupa irei para a festa do Rei?" de Tino Freitas e Ionit Zilberman, indicação do professor J.S.M.

Figura 3 - Indicação do livro "Com que roupa irei para a festa do Rei?"

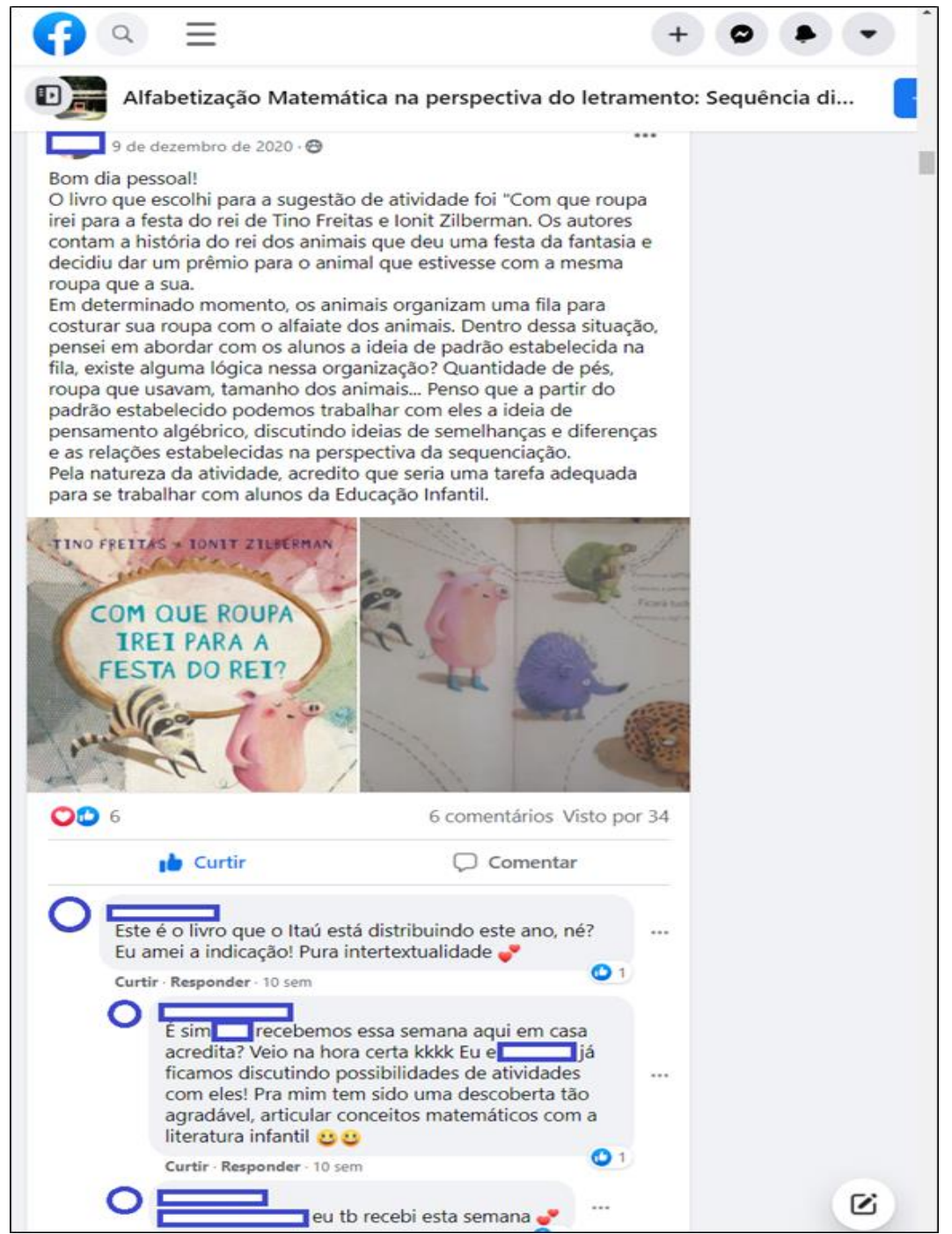

Fonte: Práticas compartilhadas na página da Web do grupo do Facebook (2021). 
Como podemos perceber, a proposta compartilhada envolve elementos do pensamento algébrico, pois o ensino e aprendizagem deste campo do conhecimento matemático vem ganhando notoriedade, desde sua propositura como sendo uma das unidades temáticas propostas pela Base Nacional Comum Curricular - BNCC (BRASIL, 2017). Embora o professor tenha o indicado para a Educação Infantil, refletimos durante os encontros síncronos que este título pode ser proposto para turmas de primeiro ano do Ensino Fundamental.

As sugestões de tarefas indicadas para o livro evidenciam a identificação de padrão, sequência, semelhanças e diferenças. Na nossa interpretação, é importante que o docente proporcione essa socialização entre as crianças fazendo questionamentos, levantando hipóteses durante o desenvolvimento da proposta e também proponha tarefas que sejam abertas, o que potencializa o desenvolvimento do pensar algebricamente em uma perspectiva de aritmética generalizada, uma vez que esses tipos de tarefas "[...] servem de contexto para ensinar outros conteúdos; podem conduzir às ideias de ordem e comparação; constituem um veículo para introduzir e interpretar símbolos, essenciais na álgebra, constituindo um contexto para desenvolver a capacidade de generalizar" (THRELFALL, 1999 apud BARBOSA; VALE, 2013, p. 3074). É importante destacar ainda que, a partir desta sugestão de título e proposta de tarefa, resultou em maior interação entre as participantes a partir dos comentários em que uma das professoras apreciou a indicação do título. No compartilhamento de sua indicação, J.S.M refletiu sobre as alternativas de trabalho com o livro e destacou positivamente o fato de poder articular literatura infantil e a Matemática ao afirmar no Facebook a importância deste recurso para socializar com os colegas.

O próximo título que elegemos aqui para discussão foi de autoria de Ana Maria Machado "Camilão, o comilão". Este conta a história de um porco esperto e guloso que não é muito "chegado" ao esforço físico e, por isso, pede alimentos a todos os bichos que encontra. Essa indicação foi da professora D.F.S que já incluiu o livro em sua prática pedagógica desde a Educação Infantil. 
Figura 4 - Indicação do livro "Camilão, o comilão".

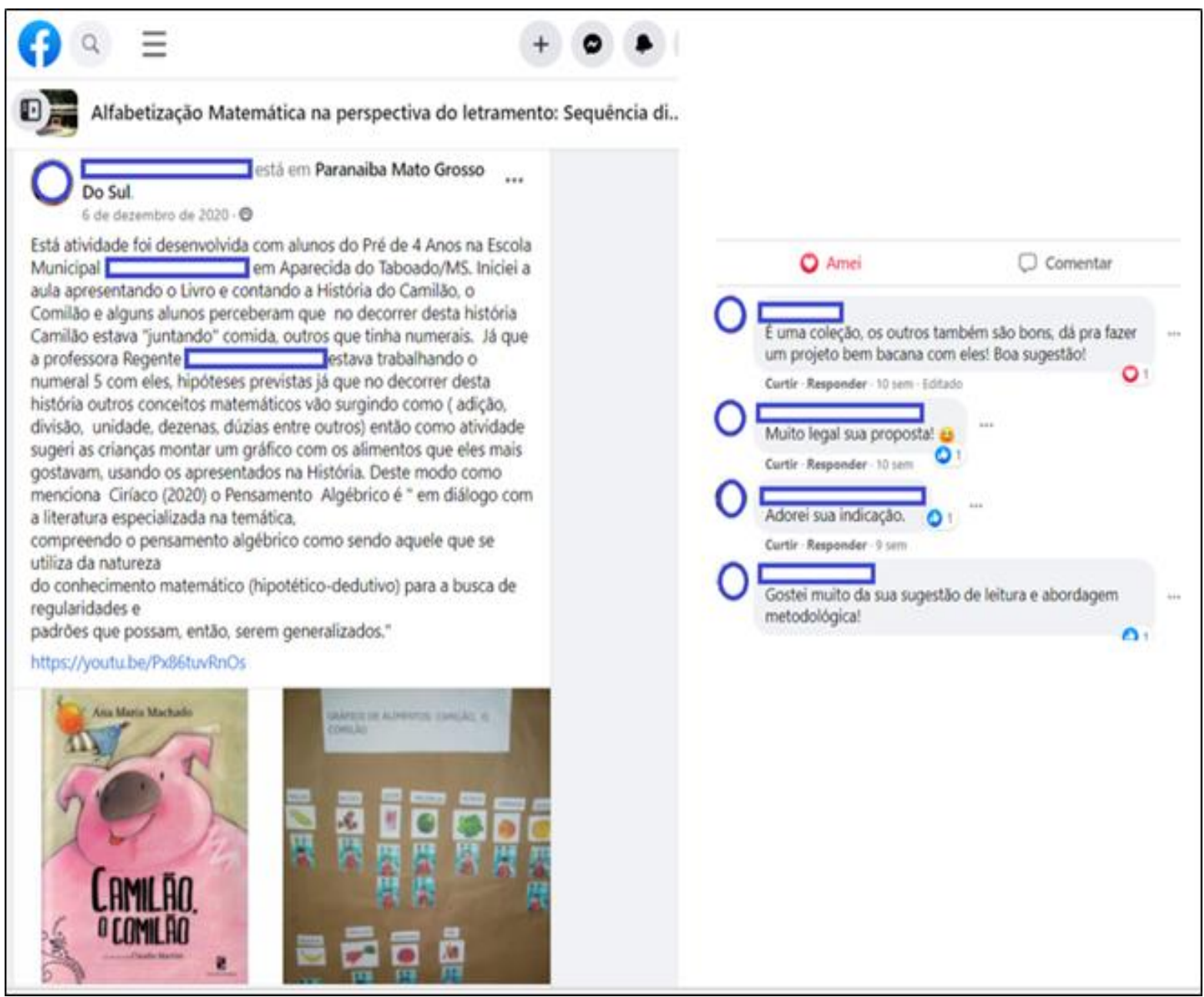

Fonte: Práticas compartilhadas na página da Web do grupo do Facebook (2021).

Segundo D.F.S, ao apresentar o livro para as crianças, percebeu que elas, mesmo sem entender certos conceitos e terem apropriação da comunicação matemática, foram capazes de dizer que o Porquinho "Comilão" da história está "juntando" comida. É fundamental que o professor tenha entendimento de "[...] reconhecer a diversidade de estruturas de problemas, analisar as operações envolvidas e as operações de pensamento necessárias para resolver cada classe de problemas" (VERGNAUD, 1982, p. 6). Situações como essa, em que a criança vai retirar, juntar e comparar exigirão maiores habilidades para resolver problemas mais complexos. Assim, é muito comum o professor ouvir a seguinte frase: "é de mais ou de menos?". As crianças ficam aflitas para saberem qual a operação usar e chegar ao resultado. Ao trazer a literatura infantil para as aulas de Matemática e propor situações-problemas, a professora apresenta uma abordagem 
diferente em relação à maneira tradicional ao lidar com os conceitos de campo aditivo, proporcionando diferentes caminhos para a resolução de problemas, o que significa oferecer à criança maiores subsídios para encarar futuramente as equações.

De forma geral, as professoras trouxeram importantes contribuições que possibilitaram interações coletivas no processo de compartilhamento de ideias no grupo da rede social Facebook. Entendemos que a formação continuada de professoras e professores é um processo contínuo e a construção desse conhecimento no espaço virtual "[...] exige uma constante interação entre os envolvidos, acaba desencadeando um movimento de interação dos diferentes conhecimentos e saberes, constituindo-se como um espaço de formação para todos os envolvidos [...]" (LOPES; SILVA; BOROWSKY; FRAGA; 2010, p. 44).

Concomitantemente, um dos textos que subsidiou a discussão propulsora foi o de Ciríaco e Santos (2020) em que os autores sinalizam o quão importante é envolver as crianças no mundo da fantasia das histórias infantis, de modo que os discursos que perpassam as narrativas auxiliam na inserção da Matemática em um processo de alfabetização na perspectiva do letramento. Destarte, ao que tudo indica, parece que ocorreu tal incorporação da literatura infantil nas aulas de Matemática e que refletir sobre essas duas áreas é uma tentativa de oferecer subsídios para que o professor inclua novas estratégias em sua prática pedagógica e "[...] ao reconhecermos que a formação do professor não se finda na formação inicial e que os desafios do trabalho pedagógico geram outras necessidades formativas, a formação continuada assume um papel decisivo [...]" (CIRÍACO, 2012, p. 245), razão pela qual defendemos o posicionamento de iniciativas de trabalho colaborativo que visam o compartilhar de experiências em ambientes interativos.

\footnotetext{
Pensamos que as redes sociais virtuais na educação são um importante recurso de comunicação, interação e compartilhamento de ideias, informações e conhecimentos de forma colaborativa, e por estas características, tornam-se uma importante ferramenta que pode ser pesquisada e explorada potencialmente na área educacional (SANTOS; MELIM; PAGIANO, p. 1617, 2017).
}

Em suma, de forma geral, podemos afirmar que a utilização de redes sociais, neste caso o Facebook, se deu como espaço importante para as interações e, dada nossa experiência com grupos de WhatsApp, sessões via Google Meet e e-mails, este demonstrou-se um dos Ambientes Virtuais de Aprendizagem mais promissores na 
experiência de formação continuada que participamos, apresentando grande potencial e um forte indicador de que o uso pedagógico deste instrumento de comunicação pode contribuir para diminuir distâncias aproximando pessoas pela dinâmica de socialização em grupo.

\section{Considerações finais}

Conceber a educação nos dias atuais é um grande desafio. A interação social e a colaboração são essenciais para a construção de conhecimento e esse movimento de partilha e compartilhamento de saberes no contexto do trabalho em grupo oportunizou aos cursistas se apropriarem de novas metodologias para que possam repensar ações já vivenciadas anteriormente no sentido de melhoria da atuação ao articular, por exemplo, a literatura e Matemática.

Logo, diante da experiência em xeque, podemos inferir que a rede social Facebook pode constituir-se espaço privilegiado de aprendizagem colaborativa durante a pandemia (e após também) e que as interações no desenvolvimento do compartilhamento de títulos literários entre o grupo de professoras em formação promoveram a reflexão dos partícipes sobre sua prática, o que trouxe significados às aulas.

\section{Referências}

BARBOSA, Ana; VALE, Isabel. A resolução de tarefas com padrões figurativos e a generalização. In: Anais... VII Congresso Iberoamericano de Educación Matemática, 2013. Montevideo. Disponível em:

<http://funes.uniandes.edu.co/19765/1/Barbosa2013A.pdf〉. Acesso em: 8, fev. 2021.

BRASIL, Ministério da Educação. Secretaria de Educação Básica. Pacto Nacional pela Alfabetização na Idade Certa. Organização do Trabalho Pedagógico. Brasília: MEC, SEB, 2014. Disponível em: <https://wp.ufpel.edu.br/antoniomauricio/files/2017/11/1_Caderno-1_pg001-072.pdf>. Acesso em: 12, abr. 2018.

BUENO, Renata. Poemas Problemas. São Paulo: Editora do Brasil, 2012.

CIRÍACO, Klinger Teodoro. Conhecimentos e práticas de professores que ensinam Matemática na infância e suas relações com ampliação do Ensino Fundamental. 2012. 334f. Dissertação (Mestrado em Educação) - Faculdade de Ciências e Tecnologia da Universidade Estadual Paulista "Júlio de Mesquita Filho". FCT/UNESP. Presidente Prudente-SP. 2012. Disponível em: 〈https://repositorio.unesp.br/handle/11449/92248>. Acesso em: 9, jan. 2021. 
CIRÍACO, Klinger Teodoro. Professoras iniciantes e o aprender a ensinar Matemática em um grupo colaborativo. 2016. 334f. Tese (Doutorado em Educação) - Faculdade de Ciências e Tecnologia da Universidade Estadual Paulista "Júlio de Mesquita Filho" - FCT/UNESP, Presidente Prudente-SP. 2016. Disponível em: <https://repositorio.unesp.br/bitstream/handle/11449/139512/ciriaco_kt_dr_prud.pdf?se quence $=3 \&$ is Allowed $=\mathrm{y}>$. Acesso em: 18, mar. 2021.

CIRÍACO, Klinger Teodoro; SANTOS, Francieli Aparecida Prates dos. Acervo paradidático do PNAIC e as possibilidades da literatura infantil em aulas de matemática nos primeiros anos. Interacções, v. 16, n. 53, p. 72-96, 2020. Disponível em: <https://revistas.rcaap.pt/interaccoes/article/view/19620>. Acesso em: 6, fev. 2021.

COHN, Maria Aparecida Figueiredo. Ensino de Matemática e histórias infantis: criando e resolvendo problemas nos anos iniciais do Ensino Fundamental. In: Anais... VII Congresso Internacional de Ensino da Matemática, p. 1 - 13, 2017. Rio Grande do Sul. Disponível em: $\langle$ http://www.conferencias.ulbra.br/index.php/ciem/vii/paper/viewFile/7462/3479> . Acesso em: 14, fev. 2021.

DAMIANI, Magda Floriana. Entendendo o trabalho colaborativo em educação e revelando seus benefícios. Educar, Curitiba, n. 31, p. 213-230, 2008. Disponível em: <https://www.scielo.br/pdf/er/n31/n31a13.pdf $>$. Acesso em: 18, mar. 2021.

DANYLUK, Ocsana. Alfabetização matemática: as primeiras manifestações da escrita infantil. Porto Alegre: Ed. EDIUPF, 2002.

FIORENTINI, Dario. Pesquisar práticas colaborativas ou pesquisar colaborativamente? In: BORBA, Marcelo de Carvalho; ARAÚJO, Jussara de Loiola. (Org.). Pesquisa qualitativa em Educação Matemática. Belo Horizonte: Autêntica, 2004. p.47-76.

FRANCO, Raquel Aparecida Soares Reis; CASTANHEIRA, Maria Lúcia. Práticas de letramento acadêmico no Facebook. Ilha do Desterro, Florianópolis, v. 69, n. 3, p. 13 28, 2016. Disponível em: <https://www.scielo.br/pdf/ides/v69n3/2175-8026-ides-69-0300013.pdf>. Acesso em: 30, jan. 2021.

FREITAS, Tino; ZILBERMAN, Ionit. Com que roupa irei para a festa do rei? São Paulo: Editora do Brasil, 2016.

HALL, Valerie; WALLACE, Mike. Collaboration as a subversive activity: a professional response to externally imposed competition between schools?

SchoolOrganisation, vol. 13, n. 2, 1993, p.101-117. Disponível em: <https://www.tandfonline.com/doi/abs/10.1080/0260136930130201>. Acesso em: 13, fev. 2021.

LOPES, Anemari Roesler Luersen Vieira; SILVA, Diaine Susara Garcez da; BOROWSKY, Halana Garcez; FRAGA, Laura Pippi. Ouvindo histórias e aprendendo Matemática. Perspectiva da Educação Matemática: Revista do Programa de Mestrado em Educação Matemática da UFMS / Universidade Federal de Mato Grosso do Sul, 
Campo Grande, v. 2, n.4, p. 43 - 56, 2010. Disponível em: <http://inma.sites.ufms.br/files/2015/08/PPGEDUMAT_matematica_vol_4_e_5.pdf>. Acesso em: 4, fev. 2021.

MACHADO, Ana Maria. Camilão, o comilão. São Paulo: Salamandra, 1977.

MOREIRA, José António; JANUÁRIO, Susana. Redes sociais e educação: reflexões acerca do Facebook enquanto espaço de aprendizagem. In: PORTO, Cristiane; SANTOS, Edméa Oliveira dos. Facebook e educação: publicar, curtir, compartilhar. Campina Grande: EDUEPB. 2014, p.67-84, Disponível em: $<$ https://www.researchgate.net/publication/333742535_Redes_sociais_e_educacao_refl exoes_acerca_do_Facebook_enquanto_espaco_de_aprendizagem>. Acesso em: 5, jan. 2021.

ORTEGA, Eliane Maria Vani; PARISOTTO, Ana Luzia Videira. Alfabetização matemática na perspectiva do letramento no Pacto Nacional pela Alfabetização na Idade Certa. Educação em Revista, Marília, v.17, p. 53-62, 2016, Edição Especial. Disponível em: <http://www2.marilia.unesp.br/revistas/index.php/educacaoemrevista/article/view/5845/ 3982>. Aceso em: 12, mai. 2018.

PIRES, Célia Maria Carolino. Currículos de Matemática: da organização linear à idéia de rede. São Paulo: FTD, 2000.

SANTOS, Rosimeire Martins Régis dos; MELIM, Ana Paula; PANIAGO, Maria Cristina Lima. Formação continuada de professores universitários na rede social facebook: interagir, trocar, dialogar, compartilhar, aprender e conviver. Interações (Campo Grande), v. 18, n. 2, p. 13-20, 2017. Disponível em: $<$ https://www.scielo.br/pdf/inter/v18n2/1518-7012-inter-18-02-0013.pdf $>$. Acesso: 7, fev. 2021.

SILVA, Aline Fabiana da; MARANGONI, Adriana Márcia; FURLAN, Daniele Ferreira; CARBONI, Bruna Regina. A Alfabetização matemática sob a perspectiva do letramento nos primeiros anos do ensino fundamental. In: Anais... III Colóquio de Práticas Letradas e IV EEMAI - UFSCar, p.1.10. 2016. Disponível em: <http://www.pnaic.ufscar.br/files/events/annals/2bdc71dcf6c0f139141480883048f986.p df>. Acesso em: 20, maio 2018.

SOARES Magda. Letramento e Escolarização. In: RIBEIRO, V. (org.). Letramento no Brasil. São Paulo: Global, 2003.

SOUZA, Ana Paula Gestoso de; CARNEIRO, Reginaldo Fernando. Um ensaio teórico sobre literatura infantil e Matemática: práticas de sala de aula. Educação Matemática Pesquisa: Revista do Programa de Estudos Pós-Graduados em Educação Matemática da Pontifícia Universidade Católica/PUC, São Paulo, v. 17, n. 2, p. 393 - 418, 2015. Disponível em: 〈https://revistas.pucsp.br/index.php/emp/article/view/17171〉. Acesso em: 14, fev. 2021. 
VERGNAUD, Gérard. Psicologia cognitiva e do desenvolvimento e pesquisas em Educação Matemática: algumas questões teóricas e metodológicas. Trad. de Weiss, J. Apresentação concedida para o grupo Canadense de Estudos em Educação Matemática na Queen’se University, Kingston, jun.1982. 